\title{
Suicídio e melancolia: seguindo as trilhas das primeiras elaborações psicanalíticas*1
}

\author{
Elisa de Santa Cecília Massa*2 \\ Cassandra Pereira França*3
}

\begin{abstract}
Este artigo apresenta as primeiras elaborações psicanalíticas acerca do tema do suicídio, primordialmente a partir dos relatos das reuniões das quartas-feiras da Sociedade Psicanalítica de Viena. Tal discussão estabelece um ponto central para a compreensão do tema do autoextermínio: sua intrínseca relação com as relações objetais e com a sexualidade inconsciente. Constata-se que há, ainda, um impasse em relação a estas elaborações, que podemos, a posteriori, atribuir à ausência de elaborações que só se construiriam mais tarde na teoria psicanalítica, a partir do advento da pulsão de morte.
\end{abstract}

Palavras-chave: Suicídio, pulsão de morte, melancolia, relações objetais

${ }^{* 1} \mathrm{O}$ presente artigo apresenta elementos da discussão aprofundada em dissertação acadêmica intitulada "Reflexos do objeto materno: do processo melancólico ao impulso suicida - as horas que separam duas mortes", de 2012, de autoria de Elisa de Santa Cecília Massa, sob orientação da Profa. Dra. Cassandra Pereira França. Tal dissertação foi defendida na Universidade Federal de Minas Gerais - Faculdade de Filosofia e Ciências Humanas, Departamento de Psicologia, Programa de Pós-graduação em psicologia. Área de concentração: Estudos Psicanalíticos.

*2 Doutoranda na Universidade Federal de Minas Gerais - UFMG (Belo Horizonte, $\mathrm{MG}, \mathrm{Br})$.

${ }^{* 3}$ Universidade Federal de Minas Gerais - UFMG (Belo Horizonte, MG, Br). 
Sabemos que o percurso trilhado por Freud na introdução do conceito de pulsão de morte provocou uma série de rearranjos na teoria psicanalítica. Os impasses surgidos na clínica tornaram necessário o retorno à teoria para compreender, dentro do modelo conceitual da psicanálise, o que se encontrava além do princípio do prazer. Ao adentrarmos o texto freudiano, percebemos que, embora o conceito de pulsão de morte só venha a ser forjado em 1920, as centelhas do que mais tarde culminariam nessa importante formulação teórica já vinham se desenvolvendo desde muito antes. Em diferentes momentos de sua obra, é possível detectar argumentos e questionamentos que, posteriormente, serão recuperados pelo autor para a construção definitiva do novo modelo pulsional. Tendo em vista o nosso objetivo de cotejar na obra freudiana quais foram os pontos de amarração de suas contribuições acerca da temática do suicídio, sigamos, cronologicamente, os importantes passos localizados em seu percurso teórico.

Já em 1901, Freud descreve, em "A psicopatologia da vida cotidiana", alguns exemplos que sugeririam a relação entre ferimentos acidentais infligidos a si mesmo e uma tendência autodestrutiva inconsciente. $\mathrm{O}$ autor explica que o impulso autopunitivo estaria sempre à espreita, aguardando uma oportunidade para se manifestar. Essas ocorrências, consideradas bastante comuns, podem ter sua intenção latente confirmada, por exemplo, pelo comedimento e tranquilidade com que os pacientes aceitam e relatam o acidente ocorrido. $\mathrm{O}$ autor acena para a possibilidade de que, para além do ato suicida, intencional, tenhamos que considerar a ocorrência de atos autodestrutivos inconscientes, que utilizariam uma oportunidade contingencial para se manifestar. 


\section{ARTIGO}

Freud (1901/1969) descreve um curioso diálogo entre ele e seu filho, que, à ocasião, contava 11 anos. O filho, inconformado por ter que permanecer acamado em razão de uma doença, ameaçou ao pai se matar. À noite, a criança mostrou um pequeno ferimento no peito, proveniente de uma pancada acidental na fechadura da porta. $\mathrm{O}$ psicanalista não se contentou com a motivação acidental do fato e recebeu de seu filho uma resposta não menos perspicaz sobre o episódio.

Diante de minha pergunta irônica - por que ele havia feito isso e o que ele pretendera com isso - a criança de 11 anos respondeu repentinamente esclarecida: "Isso foi minha tentativa de suicídio, que ameacei fazer hoje de manhã". De resto, não creio que naquela época meus filhos tenham tido acesso aos meus pontos de vista sobre autoferimentos. (pp. 221-222)

Neste caso, temos dois dados importantes. Primeiramente, a declaração do menino, que localiza, no acidente, a intenção inconsciente de ferir a si mesmo. Ao mesmo tempo, podemos localizar também o endereçamento deste ato ao seu pai, que o havia contrariado com a ordem de que permanecesse em repouso. Este aspecto, embora seja não explicitado nesse momento pelo autor, será crucial para a teoria psicanalítica, pois Freud irá afirmar, em sua construção sobre a metapsicologia da melancolia, que todo ato agressivo cometido contra si mesmo seria originalmente destinado ao outro.

A compreensão da determinação inconsciente de atos aparentemente ocasionais se estende também à investigação do ato suicida. Mesmo nesses casos, Freud (1901) afirma que a propensão ao ato esteve operando bastante tempo antes, ainda que fosse uma tendência "suprimida".

Certamente uma intenção consciente de cometer suicídio escolhe a época, o meio e a oportunidade; é inteiramente de acordo com isso que uma intenção inconsciente aguarda uma ocasião precipitante, que possa assumir uma parte da causação e, requisitando as forças defensivas do sujeito, libertar a intenção da pressão delas. (p. 222)

Freud já assinala, então, a importância de se investigar a determinação inconsciente tanto nos pequenos acidentes cotidianos quanto nos atos extremos de suicídio. E, mesmo não questionando mais profundamente o assunto, sugere a premência dessa temática do desejo inconsciente de punição, que seria mobilizado pelo sentimento inconsciente de culpa. Ficam assim estabelecidas as primeiras ideias a respeito de uma articulação que se tornará essencial para a teoria psicanalítica: o sentimento inconsciente de culpa e sua relação com a instância superegoica. 


\section{Autoagressividade e autoextermínio: primeiras observações}

Em 1910, durante as conhecidas sessões das quartas-feiras da Sociedade Psicanalítica de Viena, Freud e seus discípulos vieram a discutir um tema delicado: o suicídio de crianças. Tal escolha se deveu ao fato de que naquela ocasião houve diversos casos de suicídio de estudantes em Viena, e a imprensa acusava a escola de ser a responsável direta por tais atos, aspecto também mencionado na discussão. Para nortear o debate, a obra escolhida para ser lida foi Le suicide dans l'enfance, escrita por Baer em 1901, que traça um panorama do suicídio infantil a partir das notícias e estatísticas apresentadas pela imprensa. O grupo dedica duas sessões (20 e 27 de abril de 1910) para apresentação de um relatório sobre essa obra (realizado por um dos membros da Sociedade, o humanista Ernst Oppenheim e registrado por Otto Rank), e para abertura de uma discussão acerca do suicídio em geral. ${ }^{1}$

Ao longo da apresentação, encontramos várias críticas à obra de Baer, definida como uma compilação de dados estatísticos e, portanto, inadequada para obtenção de dados a respeito das motivações subjetivas de um suicídio. Para Oppenheim, tratava-se mais de um trabalho jornalístico do que psicológico, e Baer apenas encerraria a discussão exatamente por onde começa o problema para a psicologia.

Assim, apesar de as minutas da discussão não apresentarem consenso ou conclusão definitiva sobre o tema, marcaram pontos fundamentais de pesquisa: a relação entre suicídio, sexualidade e vivência edípica; e a importância dos estados depressivos e da história pessoal - particularmente relevante no que se refere aos primeiros anos de vida - ponto destacado por Oppenheim já nas primeiras páginas da apresentação. A descoberta feita por Freud de que os primeiros anos de vida são de importância fundamental para o desenvolvimento posterior - principalmente quando o desenvolvimento ocorre de maneira disfuncional - tem suas consequências na investigação sobre o suicídio: "podemos nos perguntar se não são precisamente os raros casos de suicídio cometidos na mais tenra idade que são os mais

${ }^{1}$ Estavam também presentes nos debates os seguintes membros da Sociedade Psicanalítica: Adler, Federn, Freud, Friedjung, Furtmüller, Heller, Hitschmann, Reitler, Sadger, Steiner, Stekel, Tausk e Wittels. 


\section{ARTIGO}

informativos"2 (Les premiers psychanalystes, 1910/1978, p. 470). Parece-nos bastante apropriada esta colocação de Oppenheim, que considera o autoextermínio infantil ainda mais significativo que o suicídio de adultos. Essa hipótese leva em conta não apenas os atos cometidos na infância, mas a convicção da psicanálise de que os primeiros anos de vida guardam uma importância capital para toda a trajetória posterior de um sujeito. Se levarmos em conta a atemporalidade do inconsciente, não resta dúvida de que as vivências da infância terão um grande peso também nos acontecimentos futuros, principalmente se envolvem a escolha pela morte. ${ }^{3}$

\section{O reflexo das complexas relações objetais}

Oppenheim ressalta que, mesmo em crianças normais, um motivo trivial como o medo de uma punição pode levar ao suicídio. Isso se deveria a uma capacidade de diferenciação falha e uma insuficiência das associações da criança, podendo levá-la a superestimar a relevância e o porte de uma determinada situação. Entre os vários exemplos citados pelos participantes da discussão, surge uma primeira pista da estreita relação entre o risco de suicídio e os quadros melancólicos:

o suicídio não se produz sempre em uma ocasião determinada, de maneira repentina e explosiva; ele aparece frequentemente também como resultado de uma depressão melancólica crônica, no curso da qual as ideias de suicídio assediam constantemente a pessoa. ${ }^{4}$ (p. 472 )

Tendo em vista as particularidades de cada caso, Oppenheim se pergunta que outros elementos inconscientes podem estar presentes em

2“"on peut se demander si ce ne sont pas précisément les rares cas de suicide commis á l'âge le plus tendre qui sont les plus informateurs" (Les premiers psychanalystes, 1910/1978, p. 470) (Todos os trechos citados desta obra são de minha tradução).

${ }^{3}$ Embora a questão da psicopatologia seja levantada ao longo do texto, ela não é colocada em destaque, considerando-se que em muitos casos a tênue distinção entre normalidade e patologia não é bem definida.

4"le suicide ne se produit pas toujours à une occasion déterminée, avec une soudaineté explosive; Il apparaît souvent comme le résultat d'une dépression mélancolique chronique, au cours de laquelle des idées de suicide assaillent constamment la personne" (p. 472). 
determinada circunstância, como nos casos em que a criança apresenta um medo exacerbado da punição dos pais. Como uma criança pode chegar a ter um medo tão excessivo da punição, a ponto de fugir em direção à morte?

$\mathrm{O}$ orador sugere, nos casos descritos, uma vinculação entre a fantasia incestuosa e o masoquismo da criança, indicando uma possibilidade interpretativa talvez insuspeitada à primeira vista. Esta teria sido a causa atribuída a um caso de uma criança que se defendia fortemente contra os castigos dos pais. $\mathrm{O}$ ato suicida do menino foi interpretado a partir da consideração de que se tratava de um garoto com fortes tendências masoquistas, de modo que o castigo teria uma equivalência com a união sexual. Assim, a ideia de receber uma palmada da mãe tinha sobre ele o efeito de uma sedução. Embora o breve exemplo não forneça mais explicações sobre o caso, a relação entre suicídio, incesto e masoquismo é bastante inquietante. ${ }^{5}$ Os psicanalistas consideram, nessa discussão que, em alguns casos, o suicídio funcionaria como uma tentativa extrema de escapar do insuportável inerente à realização da fantasia incestuosa.

Embora Baer, autor da obra discutida pelos psicanalistas de Viena, já tivesse considerado a importância das grandes perdas vividas pela criança nos casos de suicídio, o grupo acrescentou um elemento fundamental para a compreensão do papel dessas perdas. Retomando a discussão sobre dois casos apresentados por Baer, em que o suicídio infantil ocorreu logo após a morte de um dos pais, Oppenheim sustenta que a cena edipiana também se configura como um dos importantes pontos de investigação na compreensão do autoextermínio: "Um defensor da psicologia freudiana suspeita da existência de um conflito erótico nesse amor suicida da menina pelo pai e do menino pela mãe"6 (p. 474).

Uma das conhecidas características do suicídio, seu aspecto de contágio, também foi considerado, destacando que sobre as crianças o seu efeito seria ainda mais poderoso. Como a vida mental da criança careceria de

${ }^{5}$ Vemos aqui considerações que serão posteriormente trabalhadas em "Uma criança é espancada" (1919/1976b), onde Freud analisa fantasias de pacientes sobre uma cena recorrente na clínica, na qual uma criança apanha de um adulto, desvelando sua relação com o desejo incestuoso e com a masturbação.

6"Un tenant de la psychologie freudienne suspectera l'existence d'un conflit érotique dans cet amour suicidaire de la fillete pour son père et du garçon pour as mère" (p. 474). 


\section{ARTIGO}

independência, toda impressão mais forte que a atinja vinda do exterior teria sobre ela um efeito intenso. A notícia do suicídio de um parente ou de um colega de mesma idade poderia suscitar na criança o desejo de imitar esse ato. A possibilidade de um estado depressivo desconhecido pela família também deverá ser considerado, bem como o abandono nos cuidados em relação a um dos filhos.

Oppenheim anuncia outra questão importante, que será retomada por Freud anos mais tarde: o suicídio como o retorno de uma agressividade anteriormente destinada a um terceiro. "No suicídio de crianças, a vingança exercida contra os pais desempenha frequentemente um papel; trata-se de lhes fazer mal" (p. 479). Para o humanista, poucos casos ocorreriam devido a um motivo duradouro; na maior parte do tempo, tratar-se-ia de uma decisão impulsiva que seria anulada prontamente, se fosse possível. Contudo, a relevância da sexualidade não deixa de ocupar um lugar central nessa discussão:

A causa mais importante, tanto para as crianças como para os adultos, é a sexualidade. Quem não abandonou a esperança no amor não renuncia à vida. Não podemos negar o fator da hereditariedade, mas o fato que aciona [o suicídio] é, em cada caso, a falta de amor. ${ }^{9}$ (p. 479)

Sobre o amor e sua relevância na compreensão do suicídio, Oppenheim sublinha uma particularidade da adolescência no que diz respeito à relação com os pais, e consequentemente na relação transferencial que se estabelece com os professores. Seria necessário entender que o suicídio de estudantes ocorreria, segundo o humanista, na puberdade, que é caracterizada por um aumento na necessidade de amor, concomitante a um distanciamento em relação aos pais. A necessidade de amor homossexual (pelo pai) também aumentaria, criando um contexto propício para que essa necessidade amorosa

${ }^{7}$ Freud retoma amplamente esta discussão em "Luto e melancolia" (1917[1915]/1974). Nesse desejo de vingança em relação aos pais, certamente subjaz a mesma agressividade mencionada.

${ }^{8 " D a n s ~ l e ~ s u i c i d e ~ d ' ~ e n f a n t s, ~ l a ~ v e n g e a n c e ~ e x e r c e ́ e ~ s u r ~ l e s ~ p a r e n t s ~ j o u e ~ s o u v e n t ~ u m ~ r o l e ; ~ i l ~}$ s'agit de leur faire du mal" (p. 479).

9"La cause la plus importante, chez les enfants aussi bien que chez les adultes, est la sexualité. Qui n'a pas abandonné l'espoir de l'amour ne renonce pas à la vie. On ne peut certainement pas nier le facteur de l'heredité, mais le facteur qui déclenche [le suicide] est, dans chaque case, le manque d'amour" (p. 479). 
se transferisse do pai para a figura do mestre. Lembremos que no contexto da época havia uma forte relação de autoridade e hierarquia na vida escolar e uma prevalência de professores homens. Julgando ser fundamental compreender a importância do professor como figura de referência na vida de um jovem, os analistas discutiram o "grão de verdade" contido nas afirmações contra os professores enunciadas pela imprensa à época, e que bem poderiam ser levianas.

Com base nessas considerações, Oppenheim afirma que, quanto melhor os professores puderem acolher a demanda de amor de seus alunos, procurando estabelecer uma relação de autoridade e afeto, mais seguras essas crianças estarão. Para isso, é necessário que o professor possa suportar bem ser o alvo dessa demanda (o que dependeria de sua habilidade em lidar com as correntes homossexuais desse afeto) e que possa lidar com esses conteúdos sem hostilidade ou repressão. Esta articulação sugere uma ideia importante a ser desenvolvida: a ligação entre o amor parental, a maneira como essa criança foi recebida no seio familiar e suas futuras relações de objeto. No início da socialização, parece coerente supor que as primeiras relações fora da família ocorrem na escola e que os professores certamente assumem, a partir da transferência, um papel importante e correlativo àquele que os pais ocuparam primeiramente: referências de conduta, autoridade e modelos nos quais se busca afeto e aprovação. É nesse sentido que o orador nos fala da necessidade de estar atento aos termos nos quais essa relação aluno/professor ocorre.

\section{O esforço de teorização sobre a autodestruição}

Apesar de considerar que a psicanálise dava seus primeiros passos rumo à compreensão do suicídio na ocasião, Oppenheim lança uma hipótese a respeito da visão psicanalítica sobre o tema: no suicídio, "a pulsão de vida seria vencida pela libido". Essa afirmação, a princípio contraditória, se basearia na concepção de que a neurose seria "um conflito entre as pulsões egoicas e as pulsões sexuais" ${ }^{10}$ (p. 481). Deste trecho, podemos inferir que, naquele momento, se postulava uma dessemelhança entre o investimento

\footnotetext{
10“"un conflit entre la pulsion du moi et les pulsions sexuelles" (p. 481).
} 


\section{ARTIGO}

egoico e a pulsão sexual, da qual a libido seria o representante fundamental. Embora se cogite em alguns momentos da discussão uma "impulsão à autodestruição", a noção de "pulsão de morte" ainda não havia sido formulada por Freud. Talvez a insuficiência conceitual seja a responsável pelas diversas hipóteses lançadas na tentativa de abranger a aridez do tema. Contudo, vemos que há algo de inapreensível que o texto parece rondar, mas não consegue capturar, e parece-nos que essa lacuna se deve exatamente à falta deste conceito. ${ }^{11}$

Contudo, na citação a seguir, já se nota que, naquele momento, o conflito apresentado acarreta uma contradição: a presença da libido já é tida como evidência da atuação da pulsão de vida. Dessa maneira, seria incorreto opor "libido" a "preservação da vida".

À fórmula segundo a qual o suicídio é uma vitória da libido sobre a pulsão de autoconservação, deve-se acrescentar que encontramos também a libido do lado da pulsão de vida; quanto mais libido livre, maior a alegria de viver. Um indivíduo que foi desiludido [déçu] em sua libido não terá o esforço de encontrar uma sublimação substitutiva. ${ }^{12}$ (Les premiers psychanalystes, 1910/1978, pp. 486-487)

A importância da sexualidade, todavia, é amplamente explorada nesse esforço de teorização sobre a autodestruição. É necessário desvendar a sexualidade inerente às manifestações do desejo de morte. $\mathrm{O}$ orador enumera três pontos centrais nessa discussão. Primeiramente, a afirmação de que o desespero no campo amoroso leva ao suicídio e que muitos se suicidam por não conseguirem exercer plenamente sua sexualidade. $O$ segundo ponto seria aquele destacado por Freud, ao dizer que o problema do incesto estaria em primeiro plano. O terceiro fator indica a conexão inconsciente entre suicídio e masturbação:

${ }^{11}$ Porém, futuramente, a partir do conceito de narcisismo, dos rearranjos propostos em "Além do princípio do prazer" (1920/1976) e consolidados pela formulação da segunda tópica em "O ego e o id" (1923/1976d), Freud iria afirmar que também o eu é objeto da pulsão sexual e que, portanto, não seria correto separar as pulsões que investem o eu das pulsões sexuais. Assim, o conflito presente no suicídio também precisaria ser descrito em outros termos.

12“'A la formule selon laquelle le suicide est une victoire de la libido sur la pulsion d' autoconservation, il faut ajouter qu'on trouve aussi la libido du côté de la pulsion de vie; plus il y a de libido libre, plus la joie de vivre est grande. Un individu qui a eté déçu dans sa libido n'aura pas de peine à trouver une sublimation substitutive" (pp. 486-487). 
Um terceiro fator se manifesta pelo fato de que, em todos os suicidas, as ideias e tentativas de suicídio se produzem porque eles renunciaram à masturbação. O suicídio nada mais é que o ato masturbatório final ("Hand an sich legen"13). Freud deteve sua atenção sobre o fato que a masturbação só adquire sua significação através da fantasia. No entanto, essas fantasias são, na maioria dos casos, fantasias de incesto recalcadas. ${ }^{14}$ (p. 488)

O termo utilizado na língua alemã, "Hand an sich legen”, lança luz sobre um aspecto já entrevisto no que se refere ao suicídio: sua relação com a sexualidade e com a masturbação. Ao considerarmos esses dois aspectos, um terceiro se impõe: a fantasia incestuosa. Freud diversas vezes salientou a relação entre a masturbação e as fantasias incestuosas típicas da vivência infantil do complexo de Édipo. Além do enlace linguístico entre as expressões, o resumo apresenta pequenos relatos nos quais o suicídio estava, de alguma maneira, vinculado ao tabu da masturbação.

Podemos pensar na pertinência dessa relação tanto sob o viés de tabu que cada um dos assuntos comporta quanto pelas fantasias incestuosas que subjazem em ambos os casos: a mãe como objeto incestuoso fundamental da fantasia masturbatória infantil, e o sentido de retorno ao estado fusional da 296 relação primária com a mãe, muitas vezes presentes no suicídio. ${ }^{15}$

Ao fim das sessões destinadas à discussão sobre o suicídio, os psicanalistas de Viena concluem que não seria simples chegar a uma solução definitiva, e que muitas das perguntas que surgiram ao longo da discussão ainda não podiam ser respondidas. Oppenheim questiona: "o suicídio deve ser interpretado, em cada caso, como uma reação do eu ao poder superior da libido ou é

13“"Porter la main sur soi". Em português; "trazer a mão sobre si”, ou "levantar a mão contra si”. A ambiguidade se mantém nas diferentes línguas: alemão, francês e português. A expressão, que originalmente no alemão é utilizada para designar o ato suicida, também remete, em sua tradução literal, ao ato masturbatório.

${ }^{14 “}$ Un troisième facteur se manifeste dans le fait que, chez tous les suicidés, les idées et les tentatives de suicide se produisent parce qu'ils ont renoncé à la masturbation. Le suicide n'est rien que l'acte masturbatoire final ("Hand an sich legen"). Freud a attiré l'attention sur le fait que la masturbation n'acquiert as signification que par le fantasme. Cependant, ces fantasmes sont, dans la plupart des cas, des fantasmes d'incestes refoulés" (p. 488).

${ }^{15}$ Embora este tema ultrapasse a discussão pretendida neste artigo, vale lembrar a frequente associação entre a morte e a figura materna, presente nas artes e nas mitologias. Para maior aprofundamento neste tema, conferir a aludida dissertação que originou este artigo. 
preciso admitir, paralelamente, a existência de um suicídio que provém exclusivamente do eu?" "16 (p. 491) [itálicos no original]

Como vimos, há um hiato nessa investigação que só poderá ser preenchido por uma nova formulação teórica. Contudo, para o orador, algumas pistas foram alcançadas: "O acesso ao complexo do suicídio a partir de um estudo das patologias reside na melancolia, da qual a natureza nos é, por enquanto, desconhecida; seu mecanismo, em particular, não foi ainda examinado completamente"17 (p. 491) Na penúltima página da apresentação, Freud anuncia o caminho que trilhará alguns anos mais tarde. "O sentimento de culpa também está presente em outras neuroses; em todo caso, trata-se de elucidar o mecanismo específico da melancolia"18 (p. 492).

Recapitulemos, agora, algumas das conclusões oriundas dessas discussões acerca da problemática do autoextermínio. A questão da fantasia incestuosa, por exemplo, apresenta um desdobramento interessante. Primeiramente, os psicanalistas consideraram que o suicídio teria um sentido de escape à realização da fantasia incestuosa, fantasia esta que o castigo aplicado pelos pais poderia colocar em cena. Em seguida, revelou-se a conexão entre a masturbação e o ato suicida.

A partir daí, podemos inferir outro desdobramento para este ato. Ao considerarmos que a fantasia incestuosa recalcada subjaz ao ato masturbatório, devemos pensar na consequência disso na compreensão do suicídio. Talvez o autoextermínio não seja somente um escape ao insuportável dessa fantasia, mas manifeste uma satisfação ainda mais radical da mesma, uma vez que o ato suicida atualiza, ao mesmo tempo, o erotismo envolvido no desejo de punição infantil e a realização da fantasia de fusão com o objeto materno. Vimos ainda a vinculação entre suicídio e certa desesperança no amor, o que a metapsicologia melancólica virá confirmar de um ponto de vista constitucional.

16“le suicide doit-il dans chaque cas être interprété comme une réactiondu moi au pouvoir supérieur de la libido ou fait-il admettre à côté de cela existence d'um suicide qui provient exclusivement du moi?" (p. 491).

${ }^{176 " L ' a c c e ̀ s ~ a u ~ c o m p l e x e ~ d u ~ s u i c i d e ~ a ̀ ~ p a r t i r ~ d ' u n e ~ e ́ t u d e ~ d e s ~ m a l a d e s ~ r e s i d e ~ d a n s ~ l a ~ m e ́ l a n c o l i e, ~}$ dont la nature nous est pour l'instant inconnue; son mécanisme, en particulier, n'a pas encore été examine du tout" (p. 491).

18“"Le sentiment de culpabilité est aussi présent dans les autres névroses, dans tous les cas; il s'agit d'élucider le mécanisme spécifique de la mélancolie" (p. 492). 


\section{Vem à luz a estreita relação entre suicídio e melancolia}

Durante a sessão de 4 de maio de 1910, o comitê especial da Sociedade Psicanalítica de Viena demanda que Freud redija uma introdução à discussão sobre o suicídio de estudantes, pequeno texto que será posteriormente publicado entre os "Breves escritos", de 1910, com o nome de "Contribuições para uma discussão acerca do suicídio”. O tema da melancolia agora é expresso de maneira mais específica e claramente relacionado ao estudo que Freud apresenta posteriormente em "Luto e melancolia" (1917[1915]/1974):

Podemos, eu acredito, apenas tomar como nosso ponto de partida a condição de melancolia, que nos é tão familiar clinicamente, e uma comparação entre ela e o afeto do luto. Os processos afetivos na melancolia, entretanto, e as vicissitudes experimentadas pela libido nessa condição nos são totalmente desconhecidos. Nem chegamos a uma compreensão psicanalítica do afeto crônico do luto. Deixemos em suspenso nosso julgamento até que a experiência tenha solucionado este problema. ${ }^{19}$ (Freud, 1910/1978, p. 218)

Talvez a mais citada alusão ao suicídio seja a sua referência ao suicídio do melancólico, quando, em "Luto e melancolia", Freud (1917[1915]/1974) escreve:

A análise da melancolia mostra agora que o ego só pode se matar se, devido ao retorno da catexia objetal, puder tratar a si mesmo como um objeto - se for capaz de dirigir contra si mesmo a hostilidade relacionada a um objeto, e que representa a reação original do ego para com objetos do mundo externo. (p. 285)

Nesse texto, Freud relaciona o impulso suicida ao desejo de morte em relação ao objeto. $\mathrm{O}$ eu pretenderia, em seu ato contra si, atingir o objeto abandônico, ao qual está intimamente identificado. Como podemos ver,

${ }^{19}$ Foi ainda nesse mesmo texto que Freud se deteve mais especificamente sobre o tema do suicídio, buscando compreender os mecanismos psíquicos inerentes ao ato. A respeito da importância que a melancolia viria a ter na construção teórica sobre o suicídio, uma nota de rodapé possivelmente adicionada pelos editores nas minutas da Sociedade Psicanalítica de Viena chama a atenção: "É interessante notar quão prudente é Freud, ainda que ele pareça ter uma ideia da solução. Ele resolve, de fato, este problema baseando-se na melancolia" (Les premiers psychanalystes, 191/1978, p. 491). De fato, é a partir da melancolia que Freud se detém sobre o problema do suicídio em "Luto e melancolia" (1917[1915]/1974), e é nesse texto que algumas perguntas fundamentais sobre o tema foram respondidas. 


\section{ARTIGO}

embora houvesse no esforço de compreensão do autoextermínio, desde 1910, uma grande aposta no fator biológico, uma arguta hipótese já estava lançada: "No que concerne à mania de suicídio que se produz em certas famílias, pode ser que a hereditariedade desempenhe um papel, mas o fator essencial é a identificação aos outros membros da família"20 (p. 480). Ou seja, ainda que a hereditariedade seja considerada, há outro fator fundamental e é sobre ele que o psicanalista atua. A maneira como a história individual se desenvolve e os significados diversos que um sujeito constrói a partir de sua forma de ler o mundo, sempre influenciado pelos laços e desenlaces vividos por cada um este é o material sobre o qual se lança a escuta psicanalítica, e tal percepção não escapou aos analistas de Viena desde os tempos em que se radicou a ciência psicanalítica.

\section{Referências}

Freud, S. (1969). A psicopatologia da vida cotidiana. In Edição Standard Brasileira das Obras Psicológicas Completas de S. Freud (J. Salomão, trad., v. 6, pp. 13-332). Rio de Janeiro: Imago. (Trabalho originalmente publicado em 1901).

Freud, S. (1974). Luto e melancolia. Artigos sobre metapsicologia. In Edição Standard Brasileira das Obras Psicológicas Completas de S. Freud (J. Salomão, trad., v. 14, pp. 271-292). Rio de Janeiro: Imago. (Trabalho originalmente publicado em 1917[1915]).

Freud, S. (1976a). Contribuições para uma discussão acerca do suicídio. Breves Escritos. In Edição Standard Brasileira das Obras Psicológicas Completas de S. Freud (J. Salomão, trad., v. 11, pp. 217-218). Rio de Janeiro: Imago. (Trabalho originalmente publicado em 1910).

Freud, S. (1976b). Uma criança é espancada - uma contribuição ao estudo da origem das perversões sexuais. In Edição Standard Brasileira das Obras Psicológicas Completas de S. Freud (J. Salomão, trad., v. 17, pp. 223-256). Rio de Janeiro: Imago. (Trabalho originalmente publicado em 1919).

20"En ce qui concerne la manie du suicide qui se produit dans certaines familles, Il se peut que l'heredité y joue un role; mais le facteur essentiel est l'identification aux autres membres de la famille" (p. 480). 
Freud, S. (1976c). Além do princípio do prazer. In Edição Standard Brasileira das Obras Psicológicas Completas de S. Freud (J. Salomão, trad., v. 18, pp. 13-88). Rio de Janeiro: Imago. (Trabalho originalmente publicado em 1920).

Freud, S. (1976d). O ego e o id. In Edição Standard Brasileira das Obras Psicológicas Completas de S. Freud (J. Salomão, trad., v. 19, pp. 13-86). Rio de Janeiro: Imago. (Trabalho originalmente publicado em 1923).

Les premiers psychanalystes. (1978). Minutes de la Societé psychanalystique de Vienne. Tomo II. Séance du 20 avril 1910. Paris: Gallimard.

\section{Resumos}

(Suicide and melancholy: following in the tracks of the first psychoanalytic elaborations)

This paper presents the first psychoanalytic elaborations concerning the topic of suicide theme, primarily from the records of the Psychoanalytic Society of Vienna's Wednesday meetings. This discussion provides a central point for understanding the self-extermination theme: its intrinsic relationship with the object relations and with unconscious sexuality. There is still an impasse on these elaborations, which we can, retrospectively, attribute to the lack of elaborations that only later would be built in psychoanalytic theory, with the advent of the death drive.

Key words: Suicide, death drive, melancholy, object relations

(Suicide et mélancolie: sur les traces des premières élaborations psychanalytiques)

Cet article présente les premières élaborations psychanalytiques sur le thème du suicide, principalement à partir des archives des réunions du mercredi de la Société psychanalytique de Vienne. Cette discussion fournit un point central pour la compréhension du thème de l'auto-extermination: sa relation intrinsèque avec les relations d'objet et la sexualité inconsciente. Il semble qu'il y ait encore une impasse par rapport à ces élaborations, que nous pouvons, a posteriori, attribuer à l'absence d'élaborations, qui ne se construiraient que plus tard dans la théorie psychanalytique, à partir de l'avènement de la pulsion de mort.

Mots clés: Suicide, pulsion de mort, mélancolie, relations d'objet

(El suicidio y la melancolía: siguiendo las huellas de las primeras elaboraciones psicoanalíticas)

Este artículo presenta las primeras elaboraciones psicoanalíticas sobre el tema del suicidio, sobre todo a partir de los registros de las reuniones de miércoles de la Sociedad Psicoanalítica de Viena. Esta discusión proporciona un punto central para 


\section{ARTIGO}

comprender el tema del autoexterminio: su relación intrínseca con las relaciones de objeto y la sexualidad inconsciente. Parece que todavía hay un impasse en estas elaboraciones que podemos, de forma retrospectiva, asignar a la falta de elaboraciones que solo más tarde se construirían en la teoría psicoanalítica, desde el advenimiento de la pulsión de muerte.

Palabras clave: Suicidio, pulsión de muerte, melancolía, relaciones de objeto

(Selbstmord und Melancholie: auf den Spuren der ersten psychoanalytischen Untersuchungen)

Dieser Artikel stellt die ersten psychoanalytischen Untersuchungen zum Thema Selbstmord vor, entnommen hauptsächlich aus den Berichten der Treffen der „Psychologischen Mittwochsgesellschaft“ der Wiener Psychoanalytischen Vereinigung. Deren Diskussionen stellen einen zentralen Punkt für das Verständnis des Themas der Selbsttötung dar: ihre innere Beziehung zu den Objektbeziehungen und zur unbewussten Sexualität. Man stellt fest, dass diese Untersuchungen zu keinen konkreten Ergebnissen geführt haben, was rückblickend auf einen Mangel an Material zurückzuführen ist, der erst später durch die psychoanalytische Theorie und der Entwicklung des Konzepts des Todestriebes behoben wird.

Schlüsselwörter: Selbstmord, Todestrieb, Melancholie, Objektbeziehungen

自杀和忧郁症：心理分析学初创时期的一些论述

本文介紹了有關自殺问題的最早的精 神 分 析 闡 述, 主 要 來 自 維 也 納 精 神 分析學會 的 星期三例会的會議記錄。此类的讨论建立了研 究自杀问题的一个中心点: 自杀和客观存在的因素的内在关系, 以及自杀和性 欲无意识的关系。本文发现, 這些㘓述中, 还有一个死结没有获得解决。也就 是导致自杀的诸多因素相互之间的关系。但这个死结在后来才得到解开, 也就 是, 在精神分析学理论上, 对死亡冲动的分析取得了很大进展。

关键词: 自杀, 死亡冲动, 忧郁症, 客观关联。

Citação/Citation: Massa, E.S.C., França, C.P. (2016, junho). Suicídio e melancolia: seguindo as trilhas das primeiras elaborações psicanalíticas. Revista Latinoamericana de Psicopatologia Fundamental, 19(2), 287-302.

Editores do artigo/Editors: Prof. Dr. Manoel Tosta Berlinck e Profa. Dra. Sonia Leite

Recebido/Received: 8.2.2015/ 2.8.2015 Aceito/Accepted: 19.3.2015 / 3.19.2015

Rev. Latinoam. Psicopat. Fund., São Paulo, $19(2)$, 287-302, jun. 2016 
Copyright: (C) 2009 Associação Universitária de Pesquisa em Psicopatologia Fundamental/ University Association for Research in Fundamental Psychopathology. Este é um artigo de livre acesso, que permite uso irrestrito, distribuição e reprodução em qualquer meio, desde que o autor e a fonte sejam citados / This is an open-access article, which permits unrestricted use, distribution, and reproduction in any medium, provided the original authors and sources are credited.

Financiamento/Funding: As autoras declaram não terem sido financiadas ou apoiadas / The authors have no support or funding to report.

Conflito de interesses/Conflict of interest: As autoras declaram que não há conflito de interesses / The authors have no conflict of interest to declare.

\section{Elisa de Santa Cecília Massa}

Psicóloga; Mestre em Estudos Psicanalíticos e Doutoranda em Estudos Psicanalíticos pela Universidade Federal de Minas Gerais - Faculdade de Filosofia e Ciências Humanas Departamento de Psicologia (Belo Horizonte, MG, Br)

Praça Nova York, 118/303 - Sion

30315-550 Belo Horizonte, MG, Br

elisamassa09@gmail.com

\section{Cassandra Pereira França}

Doutora e Pós-doutora em Psicologia Clínica pela Pontifícia Universidade Católica de São Paulo - PUC-SP (São Paulo, SP, Br); Membro do Laboratório de Psicopatologia Fundamental da Associação Universitária de Pesquisa em Psicopatologia Fundamental - AUPPF (São Paulo, SP, Br); Professora Associada do Depto. de Psicologia da Universidade Federal de Minas Gerais - UFMG (Belo Horizonte, MG, Br).

Av. Antônio Carlos, 6627 - Pampulha

31270-901 Belo Horizonte, MG, Br

cassandrapfranca@gmail.com

This is an open-access article, which permits unrestricted use, distribution, and reproduction in any medium for non-commercial purposes provided the original authors and sources are credited. 